\title{
What is beyond the Nivolumab Monotherapy approval for advanced Hepatocellular Carcinoma?
}

\author{
Luis Mendoza* \\ Senior Medical Advisor, IQVA, Europe
}

Received: : March 21, 2018; Published: 眥 March 26, 2018

*Corresponding author: Luis Mendoza, Senior Medical Advisor Medical Strategy \& Science, Oncology-Hematology, Therapeutic Science \& Strategy Unit, IQVA

Keywords: Hepatocellular carcinoma; Immune checkpoint inhibitors; Nivolumab; FDA

\section{Editorial}

With an estimated 500,000 new cases per year, hepatocellular carcinoma (HCC) represents the third leading cause of cancer death worldwide. The incidence is rising in the west, largely due to an increasing incidence of hepatitis $C$ virus infection [1]. The majority of HCC patients are diagnosed with disease too advanced for curative treatment. Only liver resection and liver transplantation are considered curative, with poor efficiency of other modalities such as radiofrequency ablation (RFA) and transarterial chemoembolization (TACE), although this may provide a modest prolongation in survival; however, the relapse in the majority of these patients is inevitable [2]. An array of translational research and pilot clinical trials have revealed that adoptive immunotherapy's are safe by patients with HCC, but they lack efficacy [3]. Now, we are in the new era of immunotherapy's such as immune checkpoint inhibitors and CAR-T strategies, which would bring benefit to the HCC patients.

On September 22, 2017, the Food and Drug Administration granted accelerated approval to nivolumab (OPDIVO, BristolMyers Squibb Co.) for the treatment of HCC in patients who have been previously treated with sorafenib. The approval was based on a 154-patient subgroup of CHECKMATE-040 (NCT 01658878), a multicenter, open-label trial conducted in patients with HCC and Child-Pugh. A cirrhosis who progressed on or were intolerant to sorafenib. Patients received nivolumab $3 \mathrm{mg} / \mathrm{kg}$ by intravenous infusion every two weeks. The confirmed overall response rate, as assessed by blinded independent central review using RECIST 1.1, was $14.3 \%$ (95\% CI: 9.2, 20.8), with three complete responses and 19 partial responses. The response duration ranged from 3.2 to $38.2+$ months; $91 \%$ of responders had responses lasting six months or longer and 55\% had responses lasting 12 months or longer. Adverse reactions occurring in patients with HCC in CHECKMATE-040 were similar to those previously reported in product labelling, with the exception of a higher incidence of elevations in transaminases and bilirubin levels [4].

There are other immune checkpoint inhibitors that are being tested as monotherapy for efficacy and safety in HCC. Nivolumab was the first approved, but others will follow, as it has occurred in other malignancies. There is a bunch of possibilities for the treatment strategy using immune checkpoint inhibitors. Future directions point to various stages of HCC treatment, such as neo adjuvants and adjuvants after resection and ablation, combination therapy with transcatheter arterial chemoembolization, first-and second-line treatments, and all sorts of combinations with other immunotherapies, targeted molecules and novel therapies.

In the table annexed to this editorial you will find a list of ongoing clinical trials combining the immune checkpoint inhibitors with other therapies. At the top of the Table 1 are listed the trials with simultaneous blockage with anti-PD-1/PD-L1 and antiCTLA-4 antibodies, which are expected to be promising regimens in HCC immunotherapy. The high efficacy of the combination therapy was demonstrated in malignant melanoma [5]. Simultaneous inhibition of the B7-CTLA-4 pathway by an anti-CTLA- 4 antibody may increase the number of activated CD8+ T cells in lymph nodes, followed by an increase in the number of activated CD8+ $T$ cells infiltrating the tumour tissues, thereby enhancing the antitumor effects. Their combination with molecular targeted agents (e.g., sorafenib or axitinb) also appears promising. 
Table 1: Summary of ongoing trials with immune checkpoint inhibitors in HCC.

\begin{tabular}{|c|c|c|c|c|c|}
\hline $\begin{array}{l}\text { Clinicaltrial.gov } \\
\text { Identifier }\end{array}$ & $\begin{array}{l}\text { Immune checkpoint } \\
\text { inhibitor }\end{array}$ & Trial & Phase & No. & Main endpoint \\
\hline \multicolumn{6}{|c|}{ CTLA-4 + PD-1/PD-L1 } \\
\hline NCT03222076 & $\begin{array}{l}\text { ipilimumab+ } \\
\text { Nivolumab }\end{array}$ & $\begin{array}{l}\text { In patients with resectable of potentially resectable } \\
\text { HCC }\end{array}$ & II & 45 & $\begin{array}{l}\text { Safety, ORR, PFS, } \\
\text { conversion to surgery }\end{array}$ \\
\hline NCT028221754 & $\begin{array}{l}\text { Tremelimumab+ } \\
\text { Durvalumab }\end{array}$ & $\begin{array}{l}\text { Combined immune checkpoint inhibition in } \\
\text { combination with ablative therapies }\end{array}$ & $\mathrm{I} / \mathrm{II}$ & 90 & PFS, Safety \\
\hline NCT02519348 & $\begin{array}{l}\text { Tremelimumab+ } \\
\text { Durvalumab }\end{array}$ & $\begin{array}{l}\text { Study of Dervalumab with Tremelimumab, } \\
\text { durvalumab or Tremelimumab monotherapy in } \\
\text { unresectable HCC }\end{array}$ & II & 440 & Safety, ORR, OS \\
\hline \multicolumn{6}{|c|}{ PD-1/PD-L1 + other agents } \\
\hline NCT03071094 & Nivolumab & $\begin{array}{l}\text { Safety and efficacy of intratumoral Pexa-Vec combined } \\
\text { with nivolumab in first line advanced HCC }\end{array}$ & $\mathrm{I} / \mathrm{II}$ & 30 & Safety, ORR, DCR , OS \\
\hline NCT02423343 & Nivolumab & $\begin{array}{l}\text { Galunisertib (LY2157299) in combination with } \\
\text { nivolumab in advanced refractory solid tumors and in } \\
\text { recurrent or refractory HCC }\end{array}$ & $\mathrm{I} / \mathrm{II}$ & 75 & $\begin{array}{l}\text { MTD, ORR, DoR, PFS, } \\
\text { OS }\end{array}$ \\
\hline NCT03419897 & BGB-A317 & $\begin{array}{c}\text { Efficacy, safety, and pharmacokinetics of the } \\
\text { anti-PD-1 monoclonal Antibody BGB-A317 in } \\
\text { patients with previously treated hepatocellular } \\
\text { unresectablecarcinoma }\end{array}$ & II & 228 & ORR \\
\hline NCT03412773 & BGB-A317 & BGB-A317 versus sorafenib & III & 660 & PFS, OS \\
\hline NCT02942329 & SHR-1210 & $\begin{array}{l}\text { Exploratory clinical study of apatinib and SHR-1210 in } \\
\text { advanced HCC or gastric cancer }\end{array}$ & II/II & 60 & Safety, ORR, DCR, OS \\
\hline NCT03380130 & Nivolumab & Safety and efficacy of nivolumab after SIRT & II & 40 & Safety, ORR, DCR, OS \\
\hline NCT01658878 & Nivolumab & $\begin{array}{l}\text { Efficacy, safety and tolerability of nivolumab in } \\
\text { combination with other agents }\end{array}$ & $\mathrm{I} / \mathrm{II}$ & 620 & PFS, OS \\
\hline NCt02886897 & NA & $\begin{array}{l}\text { Study of combinations of dendritic cells and cytokine- } \\
\text { induced killer cell (D-CIK) immunotherapy and anti- } \\
\text { programmed death-1 in refractory solid tumors }\end{array}$ & $\mathrm{I} / \mathrm{II}$ & 50 & PFS, OS \\
\hline NCT03259867 & NA & $\begin{array}{c}\text { Combination of TATE and PD-1 inhibitor in liver } \\
\text { cancer }\end{array}$ & II & 40 & ORR, PFS, OS \\
\hline NCT02795429 & PDR001 & Study of INC280 + PDR001 & $\mathrm{I} / \mathrm{II}$ & 108 & DLT, ORR \\
\hline NCT03099564 & Pembrolizumab & Pembrolizumab + Y90 radioembolization & $\mathrm{I}$ & 30 & Safety, PFS, OS \\
\hline NCT02658019 & Pembrolizumab & Pembrolizumab in advanced HCC & II & 35 & Safety, PFS, OS \\
\hline NCT03163992 & Pembrolizumab & $\begin{array}{l}\text { Pembrolizumab as second-line after failure of } \\
\text { sorafenib }\end{array}$ & II & 60 & ORR \\
\hline NCT03062358 & Pembrolizumab & $\begin{array}{l}\text { Pembrolizumab or placebo given with the best } \\
\text { supportive care }\end{array}$ & III & 300 & PFS, OS \\
\hline NCT02988440 & PDR001 & PDR001 in combination with sorafenib & I & 50 & MTD \\
\hline NCT03101488 & KN035 & $\begin{array}{l}\text { Phase I study of KN035 in Chinese subjects with } \\
\text { advanced solid tumors \& HCC }\end{array}$ & I & 60 & DLT, ORR, PFS \\
\hline NCT03289533 & Avelumab & Avelumab in combination with axitinib & I & 20 & PK, ORR, PFS \\
\hline
\end{tabular}

In particular, the approach combining an immune checkpoint inhibitor with an existing loco regional therapy for HCC is currently under evaluation. TACE or RFA is expected to enhance the effects of immunotherapy by inducing local inflammation, releasing gneoantigens that activate antigen presentation and immune system activation. The results of the combination therapy with antiCTLA-4 antibody and loco regional therapy in advanced HCC have recently been published [6]. The NCT01853618 study evaluated the efficacy of adjuvant therapy with tremelimumab (anti-CTLA-4 antibody) after RFA or TACE in several, but not all, HCC nodules, with favourable outcomes, including a partial response rate of $26 \%$, time to tumor progression of 7.4 months, and overall survival of 12.3 months.

The results of trials of the immune checkpoint inhibitorcombined strategies are awaited with high expectations by the medical community.

\section{References}

1. El-Serag HB, Mason AC (1999) Rising incidence of hepatocellular carcinoma in the United States. N Engl J Med 340: 745-750.

2. Bruix J, Sala M, Llovet JM (2004) Chemoembolization for hepatocellular carcinoma. Gastroenterology 127(5(1)): S179-S188. 
3. Yu-Peng H, Zi-Duo L, Pankaj P, Qi Z (2015) Immunotherapy for hepatocellular carcinoma: From basic research to clinical use. World J Hepatol 7(7): 980-992.

4. FDA, US Food and drog Administartion, USA

5. Larkin J, Chiarion-Sileni V, Gonzalez R, Jean Jacques Grob, C Lance Cowey, et al. (2015) Combined nivolumaband ipilimumab or monotherapy in untreated melanoma 373: 23-34.
6. Duffy AG, Ulahannan SV, Makorova-Rusher O, Wedemeyer H, Pratt D, et al. (2017) Tremelimumabin combination with ablation in patients with advanced hepatocellular carcinoma. J Hepatol 66: 545-551.
(C) This work is licensed under Creative

To Submit Your Article Click Here:

Submit Article

DOI: $10.32474 /$ OAJOM.2018.01.000109

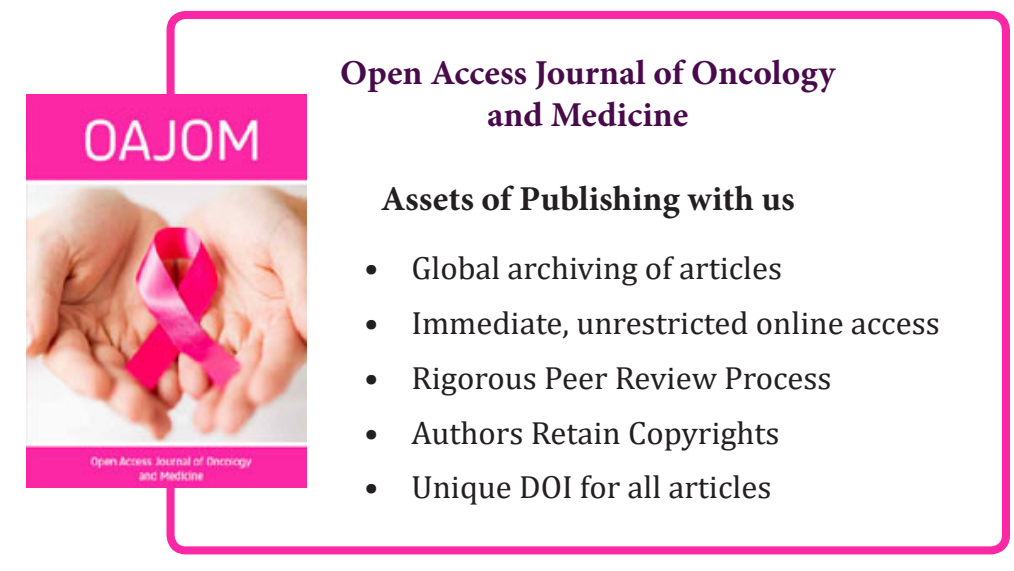

